\title{
Rheologic Properties of Erythrocytes in Duchenne Muscular Dystrophy
}

\author{
W. TILLMANN, ${ }^{\text {(921) }}$ H, G. LENARD, D. WAGNER, H. DÖNGES, AND W, SCHRÖTER \\ Department of Pediatrics, University of Göttingen, Germany
}

\section{Summary}

The transformation of erythrocytes into echinocytes by suspension in isotonic phosphate buffer was increased in patients with Duchenne muscular dystrophy (DMD) as compared to healthy controls. The transformation was enhanced when glass slides instead of polystyrole slides were used for observation.

Viscosity of erythrocyte suspensions with a hematocrit of $80 \%$ was the same in patients and controls.

The mean flow rate of erythrocyte suspensions in autologous plasma was only slightly reduced in the patient group, but decreased markedly after suspension of the cells in phosphate buffer, without as well as after preincubation with $10 \mathrm{mM} \mathrm{Na}$ salicylate. The decreased flow rate in patients is probably due to the increased number of echinocytes and not to an increased membrane rigidity, because the membrane flexibility of isolated ghosts, measured in a viscosimeter, was normal at all shear rates.

Echinocyte formation in patients with DMD is strongly dependent on the techniques applied and difficult to evaluate quantitatively by phase contrast microscopy. Filtration of erythrocyte suspensions seems to be a more reliable, quantitative test for increased erythrocyte vulnerability.

\section{Speculation}

It can be hypothesized that the red cell changes in DMD are due to the fact that the membrane of the erythrocyte contains contractile proteins similar to those of the misscle cell. These proteins may play a role for the maintenance of the biconcave shape of the erythrocyte which seems to be unstable in DMD patients.

When thoroughly washed red cells are suspended in isotonic $\mathrm{NaCl}$ and examined on a glass slide, only some of them retain a biconcave shape while others are transformed into irregularly shaped echinocytes. This reversible phenomena, called "discsphere transformation" by Ponder (12), attracted new interest of both hematologists and neurologists when Matheson and Howland (6) described an increased echinocyte formation in patients with DMD, in female carriers of the mutant gene, and in patients with other forms of progressive muscular dystrophy. These observations, however, could not be fully confirmed by other investigators $(4,7,8)$ and were revoked by Matheson et al. (5) in a more recent publication.

Besides morphologic changes, functional alterations of erythrocytes in DMD patients have been observed by Percy and Miller (11) using a micropipette technique. These authors suggest a decreased flexibility of the membrane as an explanation for their finding of an increased rigidity of the red cell.

We have reinvestigated both morphologic and functional properties of red cells in DMD patients. Echinocyte formation was studied using several experimental conditions. Deformability of intact cells was investigated by filtration through polycarbonate sieves, and flexibility of membranes by measurement of viscosity of ghost suspensions. With our methods we found an increased disc-sphere transformation in DMD patients.

Rheologic properties of patients' erythrocytes were normal in plasma, but altered when echinocyte formation was enhanced by suspension in phosphate buffer or $\mathrm{Na}$ salicylate solution.

\section{MATERIALS AND METHODS}

Diagnosis of DMD was established by clinical examination, serum creatine phosphokinase determination, electromyography, and muscle biopsy in all cases. Blood samples from patients with DMD (5-13 years old, mean age 8 years) and of healthy controls were obtained by venous puncture and the following investigations were carried out:

\section{HEMATOLOGIC INDICES}

Blood cell counts, hemoglobin content, and cell size were determined with a Coulter model B particle counter (25). Forms of erythrocytes were studied by phase contrast microscopy.

\section{ECHINOCYTE FORMATION}

Echinocyte formation was studied in $310 \mathrm{mOsmol}$ phosphate buffer with or without the addition of $10 \mathrm{mM}$ Na salicylate. All blood samples were anticoagulated by the addition of preservativefree heparin (7 IU $/ \mathrm{ml}$ blood). Blood samples were centrifuged for 10 min at $600 \mathrm{~g}$. Plasma and buffy coat were carefully removed by aspiration. Erythrocytes were washed three times for $10 \mathrm{~min}$ at $2000 \mathrm{~g}$ in $310 \mathrm{mOsmol}$ phosphate buffer $(\mathrm{pH}=7.4$ ). In some experiments cells were incubated subsequently in $310 \mathrm{mOsmol}$ phosphate buffer ( $\mathrm{pH}=7.4$ ) containing $10 \mathrm{mM}$ Na salicylate (for $30 \mathrm{~min}$ ). All procedures were carried out at $4^{\circ}$.

Of the suspensions free of $\mathrm{Na}$ salicylate, $50 \mu \mathrm{l}$ were placed on glass slides covered with glass, and on polystyrol slides (26) covered with siliconized glass. The suspensions containing $\mathrm{Na}$ salicylate were studied on polystyrol slides only. Echinocyte formation was evaluated by phase contrast microscopy. One thousand cells were counted per preparation and classified as biconcave discocytes or echinocytes I, II, and III according to Bessis (1).

\section{VISCOSITY OF GHOST SUSPENSIONS}

Viscosity measurements of ghost suspensions were carried out at a temperature of $37^{\circ}$ with a Wells-Brookfield LVT viscosimeter (27) fitted with a viscosimeter chamber modified according to Schmid-Schönbein and Heinich (14). The instrument allows shear rates between 0.39 and $78.65 \mathrm{sec}^{-1}$. Calibration was done with a standard oil ( $10 \mathrm{~A}, 5.02$ centipoise at $\left.37^{\circ}\right)(28)$.

Isolated ghosts were prepared from erythrocytes according to the method of Dodge et al. (2) with our own modifications (20) using a hypotonic $30 \mathrm{mOsmol}$ phosphate buffer solution ( $\mathrm{pH} 7.4$ ) at $4^{\circ}$. Number and apparent volume of ghosts was determined in a Coulter Counter model B as described previously (21). Forms of ghosts were observed by phase contrast microscopy. For viscosity measurements suspensions were adjusted to contain $7.2 \pm 0.2$. 
$10^{y}$ ghosts/mi corresponding to a ghost volume of about $80 \%$. Values given under results are the mean of three determinations.

\section{FILTRATION STUDIES}

Erythrocyte deformability was measured by the filtration method described by Schmid-Schönbein et al. (15). Filtration was carried out through polycarbonate sieves, type Nucleopore, with a nominal pore diameter of $5 \mu \mathrm{m}$ at $37^{\circ}(29)$. A positive filtration pressure of $5 \mathrm{~cm} \mathrm{H}_{2} \mathrm{O}$ was used. Flow rates of suspensions were calculated by measuring the time of a complete passage of $1 \mathrm{ml}$ suspension through the filter. All experiments were carried out within $4 \mathrm{hr}$ after blood collection. Values given under results are the mean of five determinations.

\section{VISCOSITY MEASUREMENTS}

Viscosity measurements of intact cells were carried out at $37^{\circ}$ on cell suspensions with a hematocrit of $80 \%$ as described by Weed et al. (24). A Wells-Brookfield LVT cone-plate viscosimeter (27) was used. The instrument allows shear rates between 1.5 and $230 \mathrm{sec}^{-1}$. It was also calibrated by the use of the standard oil described above. All experiments were carried out within $\mathbf{4} \mathrm{hr}$ of blood collection. Values given under results are the mean of three determinations.

\section{RESULTS}

\section{HEMATOLOGIC INDICES}

Data for patients $(n=18)$ were within the normal range. Erythrocyte counts ranged from 4.0-4.6 $\cdot 10^{12} / 1$, hemoglobin from $11,0-14.4 \mathrm{~g} / \mathrm{dl}$, corpuscular hemoglobin content from $28-31$ $\mathrm{pg}$, and reticulocyte counts from $0.8-1.4 \%$. There was no significant difference between the mean erythrocyte volume of patients $\left(n=18 ; 83.3 \pm 7.4 \mu \mathrm{m}^{3}\right)$ and of controls $\left(n=36 ; 85.5 \pm 5.9 \mu \mathrm{m}^{3}\right)$.

\section{ECHINOCYTE FORMATION}

Erythrocyte suspensions in autologous plasma of both patients ( $n=12$ ) and controls $(n=24)$ showed a biconcave shape (discocytes) and only a few echinocytes on glass slides as well as on polystyrol slides.

When erythrocytes were suspended in isotonic phosphate buffer, a partial transformation of cells into echinocytes was observed which was more pronounced in patients than in controls. The

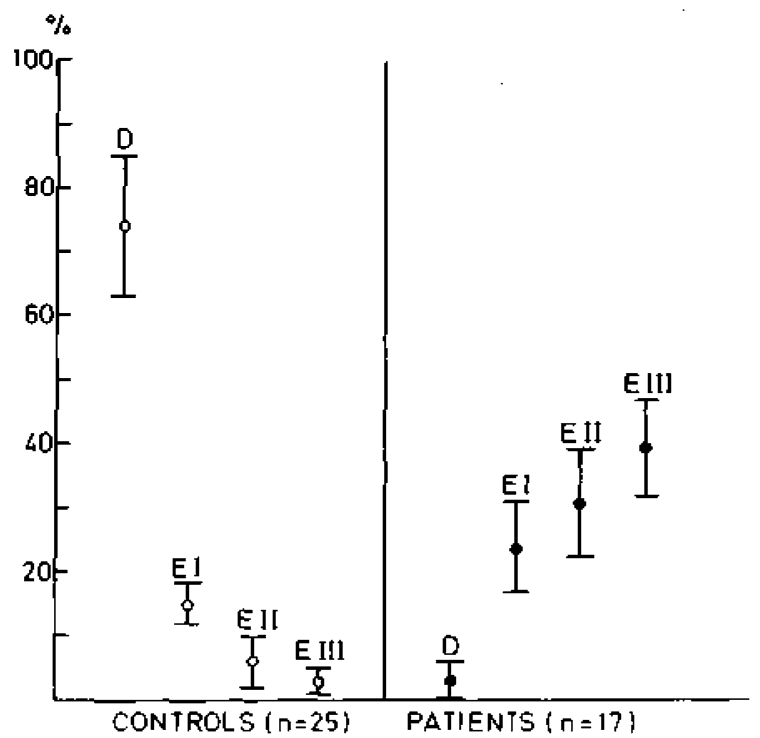

Fig. I. Formation of echinocytes on polystyrole slides after suspension of erythrocytes in isotonic phosphate buffer. D, discocytes; E, echinocyles (types l-III according to Bessis (1))

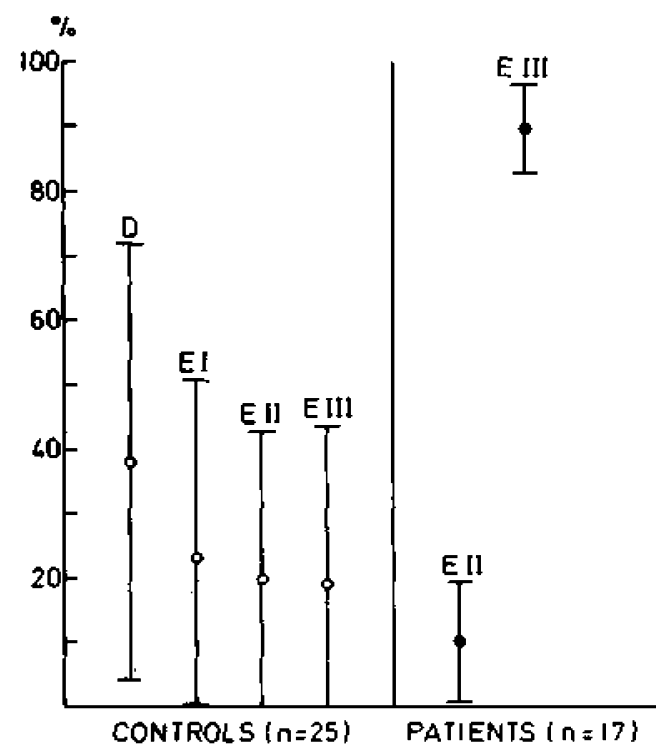

Fig. 2. Formation of echinocytes on glass slides. For description see Figure I.

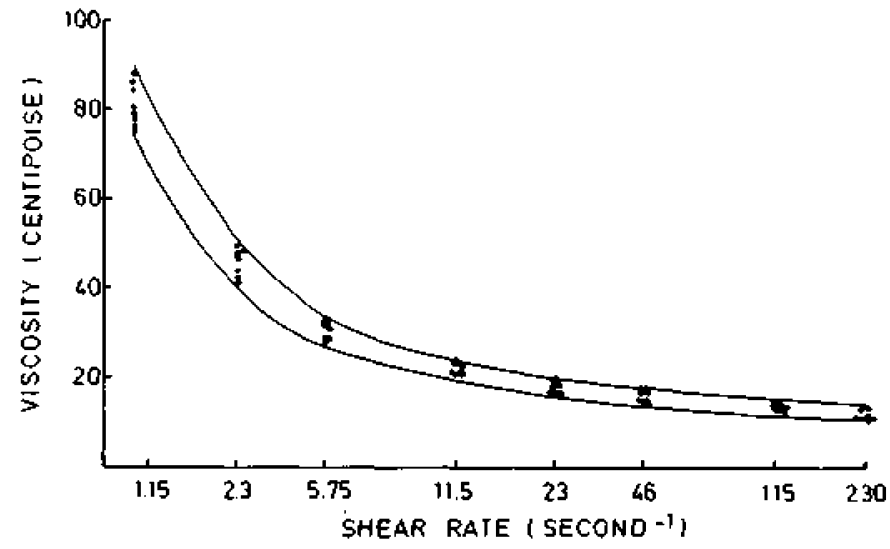

Fig. 3. Viscosity of erythrocyte suspensions (hematocrit $80 \%$ ) of patients with DMD. Solid lines indicate the range of normal controls.

transformation was enhanced in both groups when observed on glass slides (Fig. I) as compared to polystyrol slides (Fig. 2).

After incubation with $\mathrm{Na}$ salicylate, erythrocytes of both patients and controls were completely transformed into echinocytes. Morphologic classification revealed very similar degrees of transformation into echinocytes types I, II, and III. In 8 patients, the values were $18.5 \pm 12.3 \%$ type I, $39.0 \pm 14.2 \%$ type II, and 42.5 $\pm 17.8 \%$ type III; for 12 controls the corresponding values were $19.8 \pm 15.7 \%, 38.7 \pm 13.9 \%, 41.5 \pm 19.4 \%(P>0.05)$.

\section{VISCOSITY MEASUREMENTS OF ERYTHROCYTES WITH A HEMATOCRIT OF $80 \%$}

Viscosity of erythrocyte suspensions with a hematocrit of $80 \%$ of patients was within the normal range of controls (Fig. 3).

\section{FILTRATION STUDIES}

Flow rates of plasma samples of 18 patients $(81.5 \pm 12.9 \mathrm{ml} /$ sec) and of 27 controls $(83.1 \pm 14.0 \mathrm{ml} / \mathrm{sec})$ were within similar ranges. The mean flow rate of an erythrocyte suspension in autologous plasma (hematocrit $=10 \%$ ) of patients was slightly reduced (Fig. 4). As a result of a high standard deviation the difference was statistically not significant. After suspension of erythrocytes in $310 \mathrm{mOsmol}$ phosphate buffer, the mean flow rate for patients was markedly decreased in comparison to that of controls (Fig. 4). Addition of $10 \mathrm{mM} \mathrm{Na}$ salicylate to the phosphate 